\title{
Effect of different storage conditions on the quality of table eggs
}

\author{
V.Ayhan, U.S.Yamak \\ Agricultural Faculty of Ondokuz Mayis University, Department of Animal Science, \\ Samsun/Turkey
}

\begin{abstract}
The study was conducted to determine the effect of different storage conditions on egg quality characteristics of table eggs. A total of 270 eggs were collected from 80 week old Brown Lohmann Brown flock. External and internal quality traits were determined on 30 eggs and these data were used as fresh egg quality traits. And the other 240 eggs were weighed and divided into two groups of 120 eggs. For each group, 40 of eggs were washed and kept in 4 carton viols, 40 of them were kept in carton viols without washing and 40 of them were placed in carton viols and covered with stretch film. Each viol had 10 eggs. First group eggs were kept in refrigerator and second group eggs were kept in room temperature. At days of 7, 14, 21 and 28, egg quality traits were determined on 10 eggs (one viol) from each treatment. Data showed that egg weight losses were significantly higher in the eggs which were stored at room temperature $(\mathrm{P}<0.05)$. Also, washed eggs lost higher weight than other treatments. Haugh unit which is a quality parameter of eggs were significantly better in refrigerator conditions $(\mathrm{P}<0.05)$. Albumen and yolk indexes were found better in the eggs which were stored in refrigerator. The results of the study showed that egg kept in refrigerator had better quality traits than the eggs stored at room temperature. Also, keeping the eggs with stretch film had positive effect on egg quality. Conversely, egg washing decreased the quality of eggs.
\end{abstract}

Keywords: Egg, storage, egg quality, albumen, yolk

\section{Introduction}

Quality of eggs is affected by environmental conditions like storage duration, storage temperature and humidity and environmental gases. During storage, egg weight decreases due to water loss, also albumen height decreases (Jin et al., 2011). $\mathrm{CO}_{2}$ plays a vital role on albumen $\mathrm{pH}$. $\mathrm{pH}$ starts to increase right after oviposition due to gas exchanges (Brake et al., 1997). Pores on the shell allow gases to move between environments with different concentrations. All these cause spoiling of the egg. The deterioration on the quality of egg is ideally determined on yolk and albumen (Figueiredo et al., 2013). Therefore it is important to determine the changes on egg internal quality traits during storage.

In this study, eggs were kept in two different conditions with three treatments during four weeks. The changes of internal egg quality traits were determined weekly.

\section{Material and methods}

A total of 270 eggs were collected from 80 week old Brown Lohmann Brown flock. All eggs were individually numbered, weighed and egg quality traits were determined on 30 eggs. Eggs were broken on a flat surface, albumen width and length, yolk diameter and highnesses were measured with a caliper gage. $\mathrm{pH}$ of yolk and albumen were determined with a $\mathrm{pH}$ meter. Data of 
first 30 eggs were used as fresh egg quality traits. And the other 240 eggs were weighed and divided into two groups of 120 eggs. For each group, 40 of eggs were washed and kept in 4 carton viols, 40 of them were kept in carton viols without washing and 40 of them were placed in carton viols and covered with stretch film. Each viol had 10 eggs. First group eggs were kept in refrigerator and second group eggs were kept in room temperature. At days of 7, 14, 21 and 28, egg quality traits were determined on 10 eggs (one viol) from each treatment.

\section{Results and discussion}

Egg weight loss is one of the most important parameter to determine the freshness of the egg during storage. Results showed that eggs kept in room temperature lost significantly higher weight than eggs kept in refrigerator at all weeks $(\mathrm{P}<0.05$; figure 1$)$.

The albumen $\mathrm{pH}$ of the fresh eggs was reported to be between 7.6 and 8.02 (Olivera et al., 2009). The $\mathrm{pH}$ of fresh egg's albumen was determined 8.17 in this study. Eggs kept in room temperature had higher albumen $\mathrm{pH}$ at different weeks. Also, packed eggs had lower albumen $\mathrm{pH}$ (Figure1).

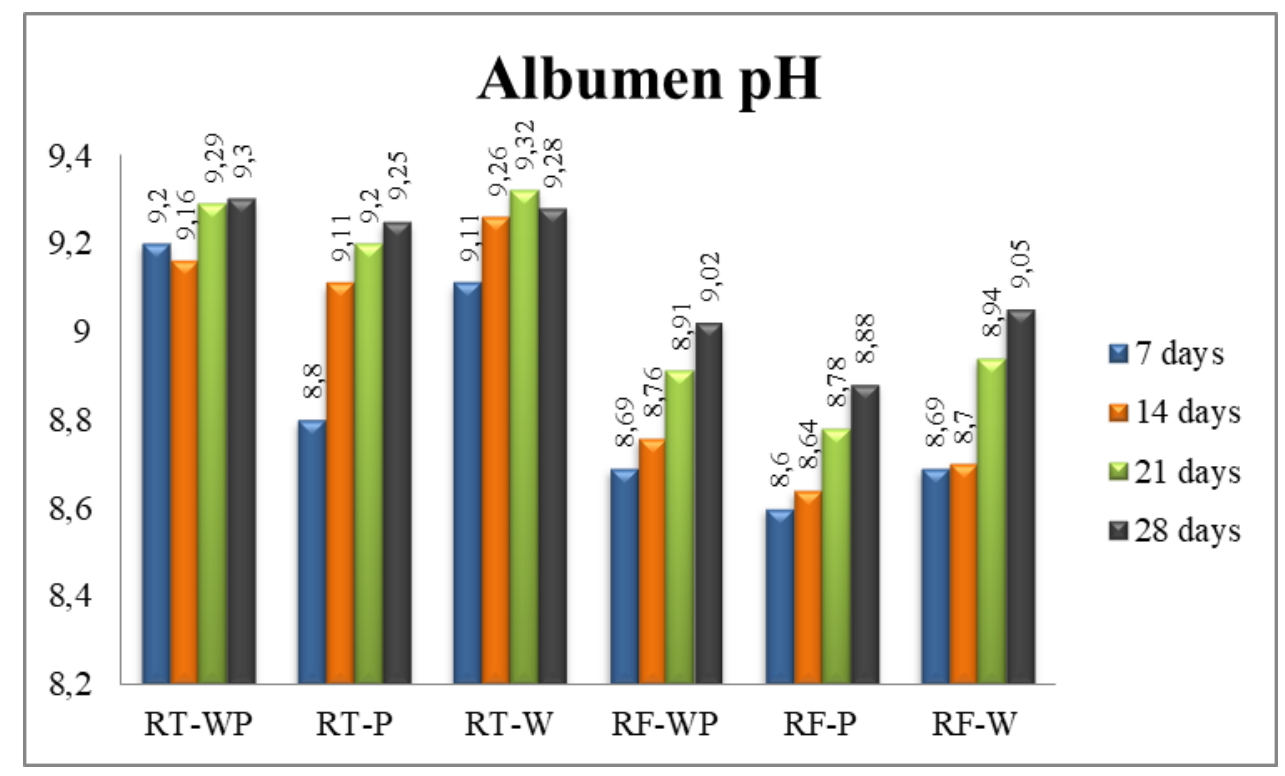

Figure 1.Changes in albumen $\mathrm{pH}$ of eggs in different conditions at different durations

RT-Room temperature, RF-Refrigerator, WP-Without package, P-Packed,W-Washed

Yolk $\mathrm{pH}$ of fresh eggs was found as 6.02. Changes during storage duration were not occurred as high as albumen $\mathrm{pH}$. Similar to albumen $\mathrm{pH}$, eggs kept at room temperature had higher yolk pH than eggs kept in refrigerator (Figure 2). Yolk and albumen indexes are the criteria to determine the quality of eggs. The mean yolk index of fresh eggs was given to be 42 (Ihekoronye and Ngoddy, 1985). In our study, we determined the yolk index of fresh eggs 44.31. The yolk indexes of eggs kept in refrigerator were found over 42 at all weeks. But yolk indexes worsen in the eggs kept at room temperature. Feddern et al., (2017) reported that the yolk index of the eggs kept in refrigerator to be over 42 during 9 weeks, but yolk index of the eggs was below 17 at 4 weeks at room temperature. 
7th International Conference on Research in Science and Technology

October $19-21,2018$

Munich - Germany

The albumen index of the fresh eggs was calculated as 8.98 in the current study. Significant differences occurred between storage conditions and eggs kept in refrigerator had significantly higher albumen indexes than the eggs kept at room temperature.

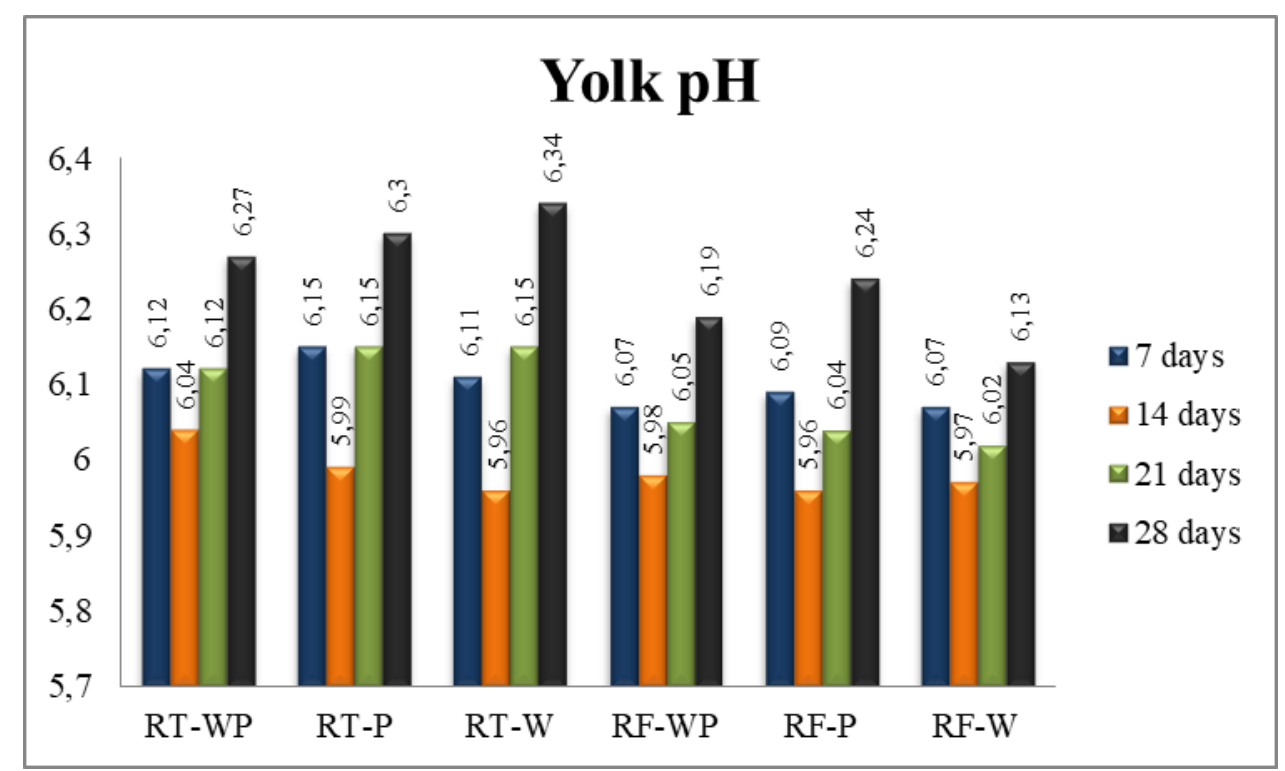

Figure 2.Changes in yolk $\mathrm{pH}$ of eggs in different conditions at different durations RT-Room temperature, RF-Refrigerator, WP-Without package, P-Packed,W-Washed

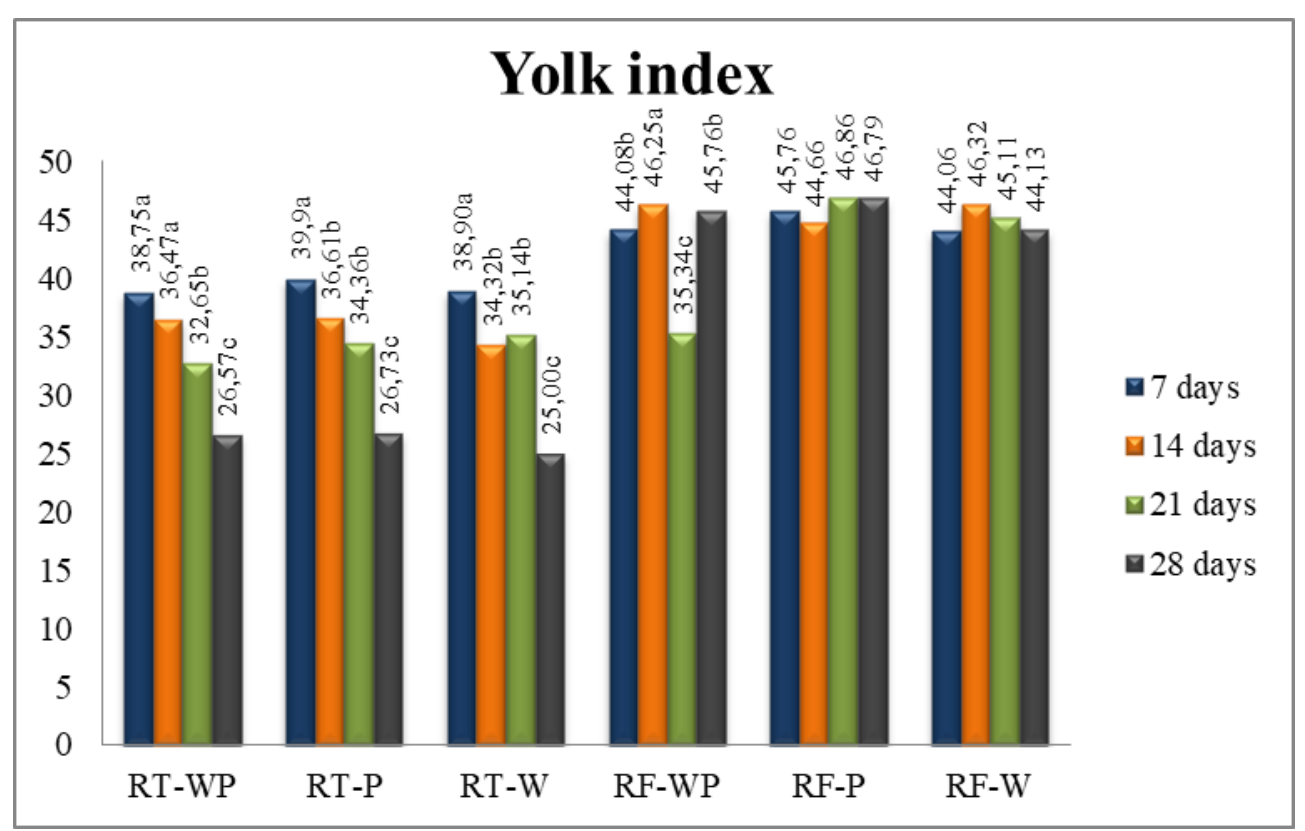

Figure 3.Changes in yolk index of eggs in different conditions at different durations RT-Room temperature, RF-Refrigerator, WP-Without package, P-Packed,W-Washed 


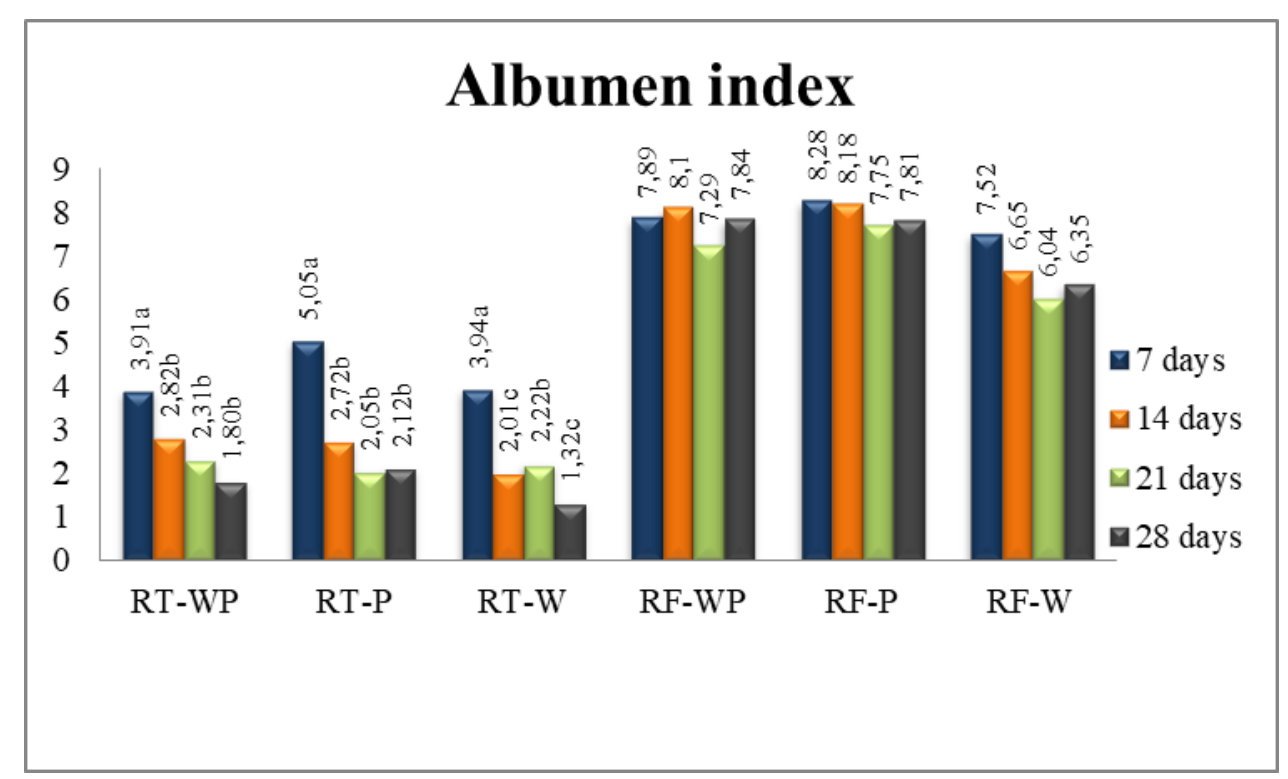

Figure 4.Changes in yolk index of eggs in different conditions at different durations RT-Room temperature, RF-Refrigerator, WP-Without package, P-Packed,W-Washed

\section{Conclusion}

As a conclusion to keep the quality traits of eggs close to fresg eggs, the eggs have to be kept in refrigerator. If possible, eggs should be kept in packages until consumption. Eggs are commonly washed before replacing to refrigerator. This also has a negative effect on the quality of eggs.

\section{References}

Brake, J.,. Walsh, T. J. C., Benton, E. J., Petitte, J. N., Meijerhof, R., Penalva, G. 1997. Egg handling and storage. Poult. Sci.76:144-151.

Feddern V., Celant De Prá M., Mores R., Nicoloso R. S., Coldebella A., Giovanni de Abreu P., 2017. Egg quality assessment at different storage conditions, seasons and laying hen strains. Ciência e Agrotecnologia 41(3):322-333.

Figueiredo T. C., Viegas R. P., Lara L. J. C., Baião N. C., Souza M. R., Heneine L. G. D., Cançado S. V.,2013. Bioactive amines and internal quality of commercial eggs., Poult. Sci., 92. 1376-1384.

Ihekoronye, P.O. and Ngoddy, A.I., 1985. Integrated food science and technology for tropics. Macmillan Press, London.

Jin, Y. H., Lee, K. T., Lee, W. I., ve Han, Y. K., 2011. Effects of storage temperature and time on the quality of eggs from laying hens at peak production. AsianAust. J. Anim. Sci. Vol. 24, No. $2: 279-284$.

Oliveira, G. E., Figueiredo, T. C., Souza, M. R., Oliveira, A. L., Cancado ,S. V., Gloria, M. B. A.. 2009. Bioactive amines and quality of egg from Dekalb hens under different storage conditions. Poultry Science 88:2428-2434. 